\title{
Symbiotic Plasmid Rearrangement in a Hyper-recombinant Mutant of Rhizobium leguminosarum biovar phaseoli
}

\author{
By GLORIA SOBERÓN-CHÁVEZ* AND REBECCA NÁJERA \\ Centro de Ingenieria Genética y Biotecnología, Universidad Nacional Autónoma de México, \\ Apdo. Postal 510-3 Col. Miraval 62271, Cuernavaca, Morelos, México
}

(Received 14 June 1988; accepted 28 September 1988)

The symbiotic plasmid of Rhizobium leguminosarum biovar phaseoli strain CFN23 has been previously shown to undergo a series of genetic rearrangements that modify the bacterial symbiotic phenotype. A hyper-recombinant derivative of strain CFN23 was isolated. This derivative (strain CFN2300) has a similar phenotype to that reported for Escherichia coli mutants defective in DNA metabolism. The frequency of CFN23 symbiotic plasmid deletion is increased in the CFN2300 background, suggesting that homologous genetic recombination is involved in the generation of this genetic rearrangement.

\section{INTRODUCTION}

Rhizobium leguminosarum biovar phaseoli is a soil bacterium that nodulates beans and fixes nitrogen in this association. As in other fast-growing rhizobia, the genetic information for the bacterium's symbiotic phenotype is plasmid-encoded (Lamb et al., 1982). The symbiotic plasmid (Sym plasmid) of $R$. leguminosarum biovar phaseoli strain CFN23 suffers a series of genetic rearrangements that modify its symbiotic phenotype. One of these rearrangements is responsible for the loss at high frequency of the nodulation ability of strain CFN23 (SoberonChávez et al., 1986).

The nitrogenase structural genes (nif genes) of $R$. leguminosarum biovar phaseoli are reiterated (Quinto et al., 1982) and the nucleotide sequences of the three copies of the nitrogenase reductase gene (nifH) that are encoded by the Sym plasmid are identical (Quinto et al., 1985). The involvement of these reiterated sequences in the genetic rearrangements described has not been established.

Some Escherichia coli mutants defective in DNA metabolism have an abnormally high frequency of homologous genetic recombination. Mutations in the genes coding for DNA polymerase I ( $p o l A)$, exonuclease VII ( $x s c)$, helicase II (uvrD), DNA ligase (lig), DNA adenine methylase (dam) and deoxyuridine triphosphatase (dut) genes have been selected on the basis of higher frequency of genetic recombination (Konrad \& Lehman, 1974; Konrad, 1977; Chase \& Richardson, 1977; Arthur \& Lloyd, 1980).

We describe here the isolation of an $R$. leguminosarum biovar phaseoli CFN23 derivative cured of an indigenous plasmid (p23a) different from the Sym plasmid. Plasmid p23a is not stably maintained in the CFN23 derivative originally isolated as cured of this plasmid (strain CFN2300). We present the characterization of strain CFN2300, showing that it has a higher frequency of homologous recombination than CFN23. The frequency of one of the CFN23 Sym plasmid rearrangements was determined in the CFN2300 genetic background.

\section{METHODS}

Bacterial strains and plasmids. These are shown in Table 1.

Microbiological procedures. All $R$. leguminosarum biovar phaseoli strains were grown on PY medium (Noel et al., 1984) at $30^{\circ} \mathrm{C}$ and $E$. coli cells on $\mathrm{LB}$ medium (Miller, 1972) at $37^{\circ} \mathrm{C}$. The antibiotic concentrations used were as 


\section{Table 1. Bacterial strains and plasmids}

Strain or plasmid

R. leguminosarum biovar phaseoli*

CFN23

CFN231

CFN2300

CFN2305

CFN2306

CFN2307

CFN2313

CFN2314

CFN2315

CFN2316

CFN2350

CFN2353

CFN2370

E. coli

1830

HB101

Plasmids

p23a

pLS151

pRK2013

pJB4JI

pRK404
Relevant characteristics $\dagger$

Wild-type strain; $\mathrm{Nod}^{+}$nifH $^{+}$

$\mathrm{Nod}^{+}$nifH $\mathrm{H}^{+}$; spontaneous $\mathrm{Str}^{\mathrm{r}}$ mutant

$\mathrm{Nod}^{-} \Delta$ nifH; cured of plasmid $\mathrm{p} 23 \mathrm{a} ; \mathrm{Km}^{\mathrm{s}} \mathrm{Str}^{\mathrm{r}}$

$\mathrm{Nod}^{+}$nifH $^{+}$; strain CFN2300 with Sym plasmid from strain CFN2315; Km $^{\text {r }}$ Str $^{r}$

Nod $^{-} \Delta$ nifH; strain CFN2300 with plasmid p23a from strain CFN2353; $\mathrm{Km}^{\mathrm{r}}$ Str $^{\mathrm{r}}$

$\mathrm{Nod}^{+}$nifH $^{+}$; strain CFN2300 with Sym plasmid from strain

CFN2314; $\mathrm{Km}^{\mathrm{r}} \mathrm{Str}^{\mathrm{r}}$

$\mathrm{Nod}^{+}$nifH $\mathrm{H}^{+}$; Tn5 inserted in plasmid p23a from strain

CFN231; $\mathbf{K m}^{\mathrm{r}}$ Str $^{\mathrm{r}}$

$\mathrm{Nod}^{+}$nifH $^{+}$; Tn $5 m o b$ inserted in Sym plasmid; $\mathrm{Km}^{\mathrm{r}} \mathrm{Rif}$

$\mathrm{Nod}^{+}$nif $^{+}$; Tn 5 mob inserted in Sym plasmid; $\mathrm{Km}^{r} \mathrm{Rif}^{\mathrm{r}}$

$\mathrm{Nod}^{+}$nifH $^{+}$; spectinomycin-resistance cassette inserted in

nifH gene of nif region $a ; \mathrm{Sp}^{\mathrm{r}} \mathrm{Rif}^{\mathrm{r}}$

Nod- $^{-} \Delta$ nifH; Rif

Nod- $^{-}$nifH; strain CFN2350 with plasmid p23a from strain

CFN2313; Km ${ }^{r}$, Rif

Nod $^{-} \Delta$ nifH; Str $^{r}$

pro met (pJB4JI)

recA13 hsdS20 rpsL

$135 \mathrm{~kb}$ CFN23 indigenous plasmid

Vector for nifH sequences; carries $\mathrm{Sp}^{r}$ and $\mathrm{Tc}^{\mathrm{r}}$

$\mathrm{Tra}^{+} \mathrm{Km}^{\mathrm{r}}$ (not transposable); unable to replicate in Rhizobium

pPHIJI ::Mu::Tn5; $\mathrm{Km}^{\mathrm{r}} \mathrm{Ge}^{\mathrm{r}}$; unable to replicate in rhizobia

Mobilizable plasmid; able to replicate in Rhizobium; $\mathrm{Tc}^{r}$
Source or reference

Soberón-Chávez et al. (1986)

This work

This work

This work

This work

This work

This work

Soberón-Chávez et al. (1986)

Soberón-Chávez et al. (1986)

This work

Soberón-Chávez et al. (1986)

This work

Soberón-Chávez et al. (1986)

Beringer et al. (1978)

Boyer \& Roulland-Dussoix (1969)

This work

Soberón-Chávez et al. (1986)

Guiney \& Helinski (1979)

Beringer et al. (1978)

Ditta et al. (1985)

* All the strains of Rhizobium leguminosarum biovar phaseoli are derivatives of strain CFN23.

$\dagger$ Nod, ability to nodulate beans; mob, gene encoding the ability to be mobilized by some transferable plasmid; nifH, nitrogenase reductase gene; $\mathrm{Tra}^{+}$, conjugative transfer ability. Resistance to streptomycin (Str ${ }^{\mathrm{T}}$ or $\operatorname{rps} L$ ), $\operatorname{kanamycin}$ $\left(\mathrm{Km}^{\mathrm{r}}\right)$, rifampicin $\left(\mathrm{Rif}^{\mathrm{r}}\right)$, spectinomycin $\left(\mathrm{Sp}^{\mathrm{r}}\right)$, tetracycline $\left(\mathrm{Tc}^{r}\right)$ and gentamicin $\left(\mathrm{Ge}^{\mathrm{r}}\right)$ and susceptibility to kanamycin $\left(\mathrm{Km}^{\mathrm{s}}\right)$ are indicated; $\mathrm{Str}^{\mathrm{r}}$ and $\mathrm{Rif}^{\mathrm{T}}$ are encoded on the chromosome; all other antibiotic resistances are plasmid-encoded. $E$. coli $\mathrm{HB} 101$ is unable to recombine, or to modify or restrict DNA. pro and met, proline and methionine auxotrophies.

follows: gentamicin $40 \mu \mathrm{g} \mathrm{ml}^{-1}$, kanamycin $60 \mu \mathrm{g} \mathrm{ml}^{-1}$, rifampicin $30 \mu \mathrm{g} \mathrm{ml}^{-1}$, spectinomycin $100 \mu \mathrm{g} \mathrm{ml}^{-1}$ and streptomycin $200 \mu \mathrm{g} \mathrm{ml}^{-1}$. To isolate strain CFN2300, two cycles of ampicillin $\left(1 \mathrm{mg} \mathrm{ml}^{-1}\right)$ and cycloserine $\left(2 \mathrm{mg} \mathrm{m}^{-1}\right.$ ) enrichment were used in the presence of $4 \mu \mathrm{g} \mathrm{kanamycin} \mathrm{ml}^{-1}$. Tn 5 insertions were selected as kanamycin-resistant transconjugants from the mating between strains 1830 and CFN23 (Table 1); plasmid pJB4JI is unable to replicate in rhizobia so the kanamycin-resistant transconjugants must contain the Tn 5 inserted in their genome. The Tn 5 insertion in plasmid p23a was identified by its ability to be transferred by conjugation to strain CFN2350 (Table 1), and the position of $\operatorname{Tn} 5$ was later corroborated by DNA hybridization using $\operatorname{Tn} 5$ as probe (data not shown).

Matings were done by plating a 1:1 mixture of the donor and recipient strains on PY medium and leaving this cross overnight. The mixture was then diluted and plated onto selective medium. The viable counts of both parents were determined from the same mixture of bacteria; three to five matings were done in parallel experiments. When we determined the frequency of transfer of the same marker to different recipient strains, a single culture of donor bacteria was used. Tn5mob insertions were mobilized with plasmid pRK2013 (Table 1).

Minimal inhibitory concentration (MIC) is the drug concentration at which bacteria were no longer able to form colonies when streaked on plates.

Isolation and manipulation of DNA. Isolation of DNA, radioactive labelling and Southern blot hybridization were done as reported by Quinto et al. (1982). The nifH probe was described previously (Quinto et al., 1985).

Plasmid visualization and purification. Plasmids were visualized as described by Eckhardt (1978). Sym plasmid was purified as described previously (Soberón-Chávez et al., 1986). It was radioactively labelled and used as probe on the plasmid profile of strain CFN23. 
Determination of DNA homologous recombination. Plasmid pLS151 is an intermediary vector derived from plasmid pSUP205 (Simon et al., 1983) which carries an $R$. leguminosarum biovar phaseoli nitrogenase reductase gene (nifH) interrupted by a DNA fragment conferring spectinomycin resistance (Soberón-Chávez et al., 1986). pLS151 is unable to replicate in rhizobia, and when introduced into an $R$. leguminosarum biovar phaseoli strain it can be maintained only as a cointegrate with nifH genes present in the bacteria. Thus by measuring the frequency of spectinomycin-resistant transconjugants from the mating between. $E$. coli HB101(pLS151) and an $R$. leguminosarum biovar phaseoli strain, the recombination frequency between pLS151 and nifH genes of that strain is determined. In the cells where only one crossover occurs the spectinomycin-resistant transconjugants retain the tetracycline resistance of pLS151. This case represents more than $90 \%$ of the transconjugants. Strain CFN2316 (Table 1) contains the nifH gene of nif region $a$, interrupted by the spectinomycin-resistance cassette. It was selected as a double recombinant between strain CFN232 (Rif derivative of strain CFN23) and pLS151; the presence of the cassette was corroborated by the DNA hybridization using nifH as probe (data not shown).

Measurements of nodulation and nitrogen fixation. These were made as reported previously (Soberón-Chávez et al., 1986).

\section{RESULTS AND DISCUSSION \\ Characterization of plasmid p23a}

$R$. leguminosarum biovar phaseoli strain CFN23 contains three indigenous plasmids, of 135 , 400 and $>450 \mathrm{~kb}$ (Fig. 1). The $400 \mathrm{~kb}$ plasmid has been shown to be the symbiotic plasmid (Soberón-Chávez et al., 1986). The $135 \mathrm{~kb}$ plasmid (p23a) shares DNA homology with the Sym plasmid, but does not contain the structural genes of the nitrogenase enzyme (nif genes) (Fig. 1).

A Tn5 insertion in p23a was isolated (see Methods); the strain carrying this plasmid is called CFN2313 (Table 1). The frequency of transfer of kanamycin resistance between strain CFN2313 and the Sym-deleted CFN23 derivative, strain CFN2350 (Table 1) is $1 \times 10^{-2}$. The transconjugants did not inherit the ability to nodulate beans nor the nitrogenase genes (nifH) (see, for example, strain CFN2353, Table 1).

\section{Isolation of strain CFN2300}

Strain CFN2300 is a kanamycin-sensitive derivative of strain CFN2313 (Table 1). It was isolated after two cycles of ampicillin enrichment for kanamycin sensitivity, and the approximate frequency of its appearance was $1 \times 10^{-6}$. Strain CFN2300 lacks plasmid p23a, is unable to nodulate beans, and lacks DNA homology with nif $H$ genes (Fig. 2). The frequency of CFN23 Sym plasmid deletion that removes nifH genes and some of the genes required for nodulation is $1 \%$ (Table 2; Soberón-Chávez, 1986), and so it seemed very likely that strain CFN2300, besides lacking plasmid p23a, carried a deleted Sym plasmid.

The Sym plasmid from strain CFN2315 (Table 1) was transferred to strain CFN2300. The transconjugants from this mating (see strain CFN2305, Table 1) are able to nodulate beans and fix nitrogen as well as strain CFN2313 even though they lack plasmid p23a. Plasmid p23a was transferred back to strain CFN2300 and the resulting strain (strain CFN2306, Table 1) remained unable to nodulate beans. From these data we concluded that plasmid p23a, though sharing DNA homology with the Sym plasmid, is not required for the establishment of the symbiosis between $R$. leguminosarum biovar phaseoli strain CFN23 and common bean.

The presence of plasmid p23a has no effect on the bacteria's symbiotic phenotype tested under laboratory conditions, even though p23a has a high degree of DNA sequence homology with the Sym plasmid (Fig. 1). It is intriguing that a plasmid with similar characteristics to plasmid p23a - in terms of its size, transfer ability and DNA homology with the Sym plasmid - is present in about half of the Mexican isolates of $R$. leguminosarum biovar phaseoli (data not shown), and that it does not seem to have a role in the symbiosis.

Plasmid p23a is transferred at a high frequency, so we think that it might participate in the conjugal mobilization of the entire Sym plasmid or of part of it, acting as a 'vector' of symbiotic information. We have preliminary evidence suggesting that the transfer frequency of the Sym plasmid is enhanced by the presence of p23a, which might thus act as a helper for Sym plasmid transfer; this might be the reason for its wide distribution among $R$. leguminosarum biovar phaseoli strains. 


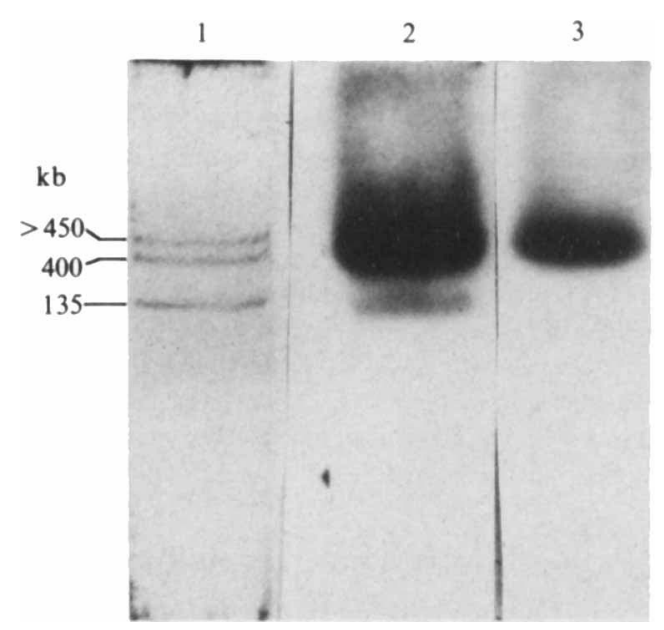

Fig. 1. Plasmid electrophoretic profile of strain CFN23 (lane 1), and hybridization of this profile with the Sym plasmid as a probe (lane 2) and with a nifH probe (lane 3 ).
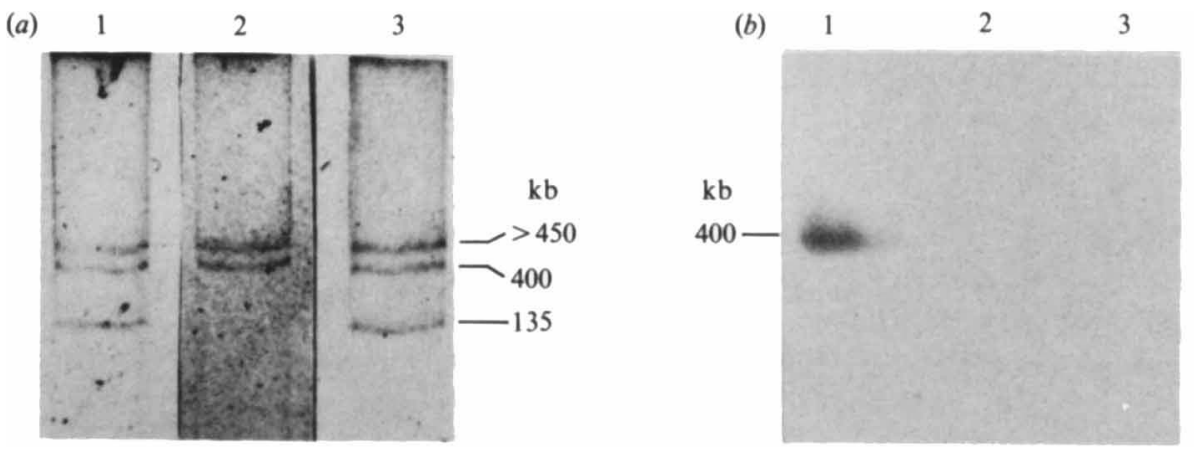

Fig. 2. Plasmid electrophoretic profile of strain CFN23 and derivatives (a) and their hybridization with a nifH probe (b). Lanes: 1, strain CFN23; 2, strain CFN2300; 3, strain CFN2370.

\section{Characterization of strain CFN2300}

The kanamycin resistance of strain CFN2306 is lost at a high frequency while that of strain CFN2353 or strain CFN2313 is not (Table 2). The instability of plasmid p23a in the CFN2300 genetic background suggested to us that strain CFN2300 contained a spontaneous mutation affecting the maintenance of this plasmid.

Certain $E$. coli strains mutant for genes whose products are involved in the SOS response have an increased sensitivity to nalidixic acid (Drlica, 1984). We tested the nalidixic acid sensitivity of strain CFN2300 relative to that of the wild-type CFN23 strain, and of its derivative with the deleted Sym plasmid (CFN2370, Table 1). Strain CFN2300 is nalidixic acid sensitive. This sensitivity is independent of the presence of plasmid p23a, since strain CFN2306 is sensitive to this antibiotic, even when grown in the presence of kanamycin where the maintenance of $\mathrm{p} 23 \mathrm{a}$ is selected (Table 3). The nalidixic acid sensitivity of strain CFN2300 is not due to the deletion affecting its Sym plasmid, since strain CFN2370, which harbours a deleted Sym plasmid (Soberón-Chávez et al., 1986), is as resistant to nalidixic acid as the wild-type strain CFN23, and strain CFN2305 is as sensitive as strain CFN2300 (Table 3). We have found that $R$. leguminosarum biovar phaseoli is naturally resistant to high levels of nalidixic acid (data not 
Table 2. Stability of plasmid p23a and the Sym plasmid in different genetic backgrounds

\begin{tabular}{ll} 
Strain & \multicolumn{1}{c}{ Plasmid where Tn5 is inserted } \\
CFN2305† & Sym plasmid (same insertion as in strain CFN2315) \\
CFN2313 & Plasmid p23a \\
CFN2306† & Plasmid p23a (same insertion as in strains CFN2313 and CFN2353) \\
CFN2307 $\dagger$ & Sym plasmid (same insertion as in strain CFN2314) \\
CFN2314 & Sym plasmid \\
CFN2315 & Sym plasmid \\
CFN2353 & Plasmid p23a
\end{tabular}

* Means of three determinations; for results $\geqslant 1 \%$, the range of values obtained is given in parentheses. † CFN2300 genetic background.

Table 3. Drug sensitivity of strain CFN2300 and its derivatives

\begin{tabular}{ccccc} 
Strain & \multicolumn{4}{c}{ Minimal inhibitory concentration* } \\
\cline { 2 - 5 } & $\begin{array}{c}\text { EMS } \\
(\%, \mathrm{v} / \mathrm{v})\end{array}$ & $\begin{array}{c}\text { Nal } \\
\left(\mu \mathrm{g} \mathrm{ml}^{-1}\right)\end{array}$ & $\begin{array}{c}\text { Rif } \\
\left(\mu \mathrm{g} \mathrm{ml}^{-1}\right)\end{array}$ & $\begin{array}{c}\text { Amp } \\
\left(\mu \mathrm{g} \mathrm{ml}^{-1}\right)\end{array}$ \\
CFN2300 & 0.04 & 200 & 5 & 10 \\
CFN2305 & 0.04 & 200 & ND & ND \\
CFN2306 & 0.04 & 200 & 5 & 10 \\
CFN2315 & 0.09 & $>400$ & ND & ND \\
CFN2370 & 0.09 & $>400$ & 5 & 10
\end{tabular}

* EMS, ethyl methane sulphonate; Nal, nalidixic acid; Rif, rifampicin; Amp, ampicillin; ND not determined.

shown). This explains the high levels of resistance of the strains used in this work. Even strain CFN2300 and its derivatives, which are reported as being sensitive to nalidixic acid, are able to grow, at a reduced rate, in concentrations as high as $180 \mu \mathrm{g} \mathrm{ml}^{-1}$. The concentration at which growth of the wild-type strain is arrested was not determined, but it is higher than $400 \mu \mathrm{g} \mathrm{ml}^{-1}$.

Bacteria bearing a mutation in one of the genes which participate in DNA replication, repair or methylation have an increased sensitivity to different mutagens. We determined the sensitivity to ethyl methane sulphonate (EMS) of strain CFN2300 and its derivatives compared to the wild-type strain, and were able to show that the mutation present in strain CFN2300 renders it sensitive to this mutagen, and that this sensitivity is independent of the presence of plasmid p23a or of the undeleted Sym plasmid (Table 3).

To rule out the possibility that the increased sensitivity to EMS and nalidixic acid was due to increased membrane permeability of strain CFN2300, we determined the sensitivity of this strain to ampicillin and rifampicin; we chose these antibiotics because $E$. coli mutants defective in DNA metabolism do not show an increased sensitivity to them. The mutation present in strain CFN2300 does not affect the level of resistance of this strain to ampicillin or rifampicin (Table 3), suggesting that this mutation affects DNA metabolism.

$E$. coli derivatives bearing a defect in some genes involved in DNA metabolism, such as lig, polA, dam, xsc, xth, uvrE or uvrD, exhibit an abnormally high frequency of homologous recombination, Zeig et al. (1978). We determined the frequency of homologous recombination of strain CFN2305 (the CFN2300 derivative containing the Sym plasmid) compared to that of strain CFN2315 (Table 1) by measuring the frequency of recombination between the nifH genes present in both strains and a cloned nifH gene carrying a segment of DNA conferring spectinomycin resistance (plasmid pLS151). Strain CFN2305 has a frequency of homologous recombination 7.1 times higher than that of strain CFN2315 (Table 4). The frequency of insertion of pLS151 in the absence of nifH genes was determined, to discriminate between homologous genetic recombination and random insertion of this plasmid. When strain CFN2300 was used as recipient for plasmid pLS151, we found a frequency of $1.9 \times 10^{-8}$ 
Table 4. Frequency of homologous recombination

$\begin{array}{cc}\text { Strain } & \begin{array}{c}\text { Frequency* of Sp } \\ \text { transconjugants in } \\ \text { matings with HB101(pLS151) }\end{array} \\ \text { CFN2315 } & 3.5 \pm 0.7 \times 10^{-6}(100 \%) \\ \text { CFN2305 } & 2.5 \pm 0.3 \times 10^{-5}(710 \%) \\ \text { CFN2300 } & 1.9 \pm 1.4 \times 10^{-8} \uparrow(0.5 \%)\end{array}$

\footnotetext{
* Mean of five determinations, \pm SE. Percentage values relative to CFN2315 are shown in parentheses.

† This value represents the CFN2300 spontaneous mutation rate to spectinomycin resistance, since all the bacteria are sensitive to tetracycline.
}

spectinomycin-resistant bacteria and all of them were sensitive to tetracycline (Table 4), showing that they were not transconjugants. We conclude that the frequency of pLS151 insertion not due to homologous genetic recombination is less than the CFN2300 spontaneous mutation rate to spectinomycin resistance.

Strains CFN2305 and CFN2315 are equally efficient as recipients of mobilized small plasmids. The frequencies of their inheritance of plasmid pRK404 using E.coli HB101 as donor strain (Table 1) are $6 \times 10^{-3}$ and $7.4 \times 10^{-3}$ respectively; thus the difference in the frequency of their inheritance of the pLS151 spectinomycin resistance seems to be due to differences in their recombination rates.

Several hyper-recombinant $E$. coli mutants show elevated mutagenesis. In parallel experiments, we determined the spontaneous mutation rate to rifampicin resistance of strains CFN2300 and CFN2370 as $4.1 \pm 0.8 \times 10^{-7}$ and $4.0 \pm 1.1 \times 10^{-8}$, respectively (means $\pm \mathrm{SE}$; $n=3$ ). This result gives additional evidence in support of our hypothesis of CFN2300 being a hyper-recombinant mutant.

The CFN2300 phenotype presented here is similar to that of certain E.coli mutants affected in DNA replication or repair (De Lucia \& Cairns, 1969; Gross \& Gross, 1969; Kinsbury \& Helinski, 1973; Lehman \& Chien, 1973; Konrad \& Lehman, 1974; Chase \& Richardson, 1977; Drlica, 1984; Bassett \& Kushner, 1985; Charon et al., 1985; Smith, 1988), but the precise defect of strain CFN2300 remains to be established.

\section{Sym plasmid deletion in the genetic background of strain CFN2300}

Strain CFN2300 has a higher frequency of homologous genetic recombination than strain CFN2315 (Table 4). Thus if the Sym plasmid deletion reported (Soberón-Chávez et al., 1986) is a product of recombination between reiterated DNA sequences, this genetic rearrangement should be increased in the CFN2300 background.

The Tn 5 mob insertion present in the Sym plasmid of strain CFN2315 (Table 1) is lost when the nodulation ability and nifH genes are deleted, whereas the Tn $5 m o b$ present in the Sym plasmid of strain CFN2314 (Table 1) is not affected by the deletion of this plasmid (SoberónChávez et al., 1986).

The frequency of Sym plasmid deletion in the CFN2300 background was measured by determining the frequency of kanamycin-sensitive derivatives of strain CFN2305 (Table 1) compared to that of strain CFN2315; Sym plasmid deletion was increased 20-fold in the CFN2300 background (Table 2).

In order to distinguish between Sym plasmid deletion and its segregation, the frequency of kanamycin-sensitive derivatives of strain CFN2307 (Table 1) was determined; CFN2307 is a CFN2300 derivative containing the CFN2314 Sym plasmid, thus its kanamycin resistance is not affected by the Sym plasmid deletion. The results obtained (Table 2) show that the Sym plasmid is stably replicated in the CFN2300 background. To rule out the possibility that increased Sym plasmid deletion in the CFN2300 background was due to the absence of plasmid p23a, we determined the rate of Sym plasmid deletion in the genetic background of strain CFN2306. This was done by measuring the frequency of spectinomycin-sensitive ( $\mathrm{Spc}^{\mathrm{s}}$ ) derivatives from strain CFN2306 carrying the CFN2316 Sym plasmid. These bacteria were 
grown in the presence of kanamycin, thus selecting for the presence of plasmid p23a. We found a frequency of $28 \% \mathrm{Spc}^{\mathrm{s}}$ cells; thus the increased frequency of Sym plasmid deletion in the CFN2300 background does not seem to be related to the absence of plasmid p23a.

Strain CFN23 presents a genetic rearrangement that results in loss of the bacterium's nodulation ability and deletion of the nitrogenase structural genes without an apparent change in the Sym plasmid molecular mass (Soberón-Chávez et al., 1986). It has been proposed that this rearrangement is due to homologous recombination between reiterated DNA sequences, which are very common among Rhizobium isolates (Flores et al., 1987). The enhanced frequence of Sym plasmid deletion in the CFN2300 genetic background led us to the conclusion that recombination between homologous DNA sequences present in this plasmid might indeed be involved in the generation of the deletion leading to the instability of CFN23 symbiotic properties.

The authors wish to thank Alicia González and Lorenzo Segovia for critical reading of the manuscript. Partial financial support for this research was provided by a grant from the Fondo de Estudios e Investigaciones Ricardo J. Zevada.

\section{REFERENCES}

ARTHUR, H. M. \& Lloyd, R. G. (1980). Hyper recombination in uvrD mutants of Escherichia coli K-12. Molecular and General Genetics 180, 185191.

BassetT, C. L. \& Kushner, S. R. (1985). Exonuclease I, III and V are required for stability of ColE1related plasmids in Escherichia coli. Journal of Bacteriology 157, 661-664.

Beringer, J. E., Beynon, J. L., Buchanan WollasTON, A. V. \& Johnston, A. W. B. (1978). Transfer of the drug resistance transposon Tn5 to Rhizobium. Nature, London 276, 633-634.

BOYeR, H. B. \& Roulland-Dussoix, D. (1969). A complementation analysis of the restriction and modification of DNA in Escherichia coli. Journal of Molecular Biology 41, 459-472.

Charon, P. R., Kushner, S. R. \& Grossman, L. (1985). Involvement of helicase II (uvrD) and DNA polymerase $I$ in the excision process mediated by the uvr $A B C$ protein complex. Proceedings of the National Academy of Sciences of the United States of America 82, 633-637.

Chase, J. W. \& Richardson, C. C. (1977). Escherichia coli mutants deficient in exonuclease VII. Journal of Bacteriology 129, 934-947.

De LuCIA, P. \& CAIRNS, J. (1969). Isolation of an E. coli strain with a mutation affecting DNA polymerase. Nature, London 224, 1164-1166.

DitTa, G., Schmidhauser, T., Yakobson, E., Lu, P., Liang, X., Finlay, D. R., Guiney, D. \& Helinski, D. R. (1985). Plasmids related to the broad host range vector, pRK290, useful for gene cloning and for monitoring gene expression. Plasmid 13, 149153.

DrLICA, K. (1984). Biology of bacterial deoxyribonucleic acid topoisomerases. Microbiological Reviews 48, 273-289.

ECKHARDT, T. (1978). A rapid method for the identification of plasmid deoxyribonucleic acid in bacteria. Plasmid 1, 584-588.

Flores, M., González, V., Brom, S., Martínez, E., Piñero, D., Romero, D., Dávila, G. \& Palacios, R. (1987). Reiterated DNA sequences in Rhizobium and Agrobacterium. Journal of Bacteriology 169, 5782-5788.
Gross, J. \& Gross, M. (1969). Genetic analysis of an E. coli strain with a mutation affecting DNA polymerase. Nature, London 224, 1166-1168.

Guiney, D. G. \& Helinski, D. R. (1979). Molecular nature of two non-conjugative plasmids carrying drug resistance genes. Journal of Bacteriology 117, 619-630.

Kinsbury, D. T. \& Helinski, D. R. (1973). Temperature sensitive mutants for the replication of plasmids in Escherichia coli: requirement for deoxyribonucleic acid polymerase I in the replication of plasmid ColE. Journal of Bacteriology 114, 1116-1124.

KONRAD, E. B. (1977). Method for the isolation of Escherichia coli mutants with enhanced recombination between chromosomal duplications. Journal of Bacteriology 130, 167-172.

KonRAD, E. B. \& LEHMAN, I. R. (1974). A conditional lethal mutant of Escherichia coli K12 defective in the 5'-3', exonuclease associated with DNA polymerase I. Proceedings of the National Academy of Sciences of the United States of America 71, 2048-2051.

Lamb, J. W., Hombrecher, G. \& Johnston, A. W. B. (1982). Plasmid determined nodulation and nitrogen fixation abilities in Rhizobium phaseoli. Molecular and General Genetics 186, 449-452.

Lehman, I. R. \& ChIEN, J. R. (1973). Persistence of deoxyribonucleic acid polymerase $I$ and its $5^{\prime}-3^{\prime}$ exonuclease activity in PolA mutants in Escherichia coli K12. Journal of Biological Chemistry 248, $7717-$ 7723.

Miller, J. H. (1972). Experiments in Molecular Genetics, pp. 431-435. Cold Spring Harbor, NY: Cold Spring Harbor Laboratory.

Noel, K. D., SánChez, F., Fernández, L., LeEmans, J. \& Cevallos, M. A. (1984). Rhizobium phaseoli symbiotic mutants with transposon $\operatorname{Tn} 5$ insertions. Journal of Bacteriology 158, 148-155.

Quinto, C., de la Vega, H., Flores, M., Fernández, L., Ballado, T., Soberón, G. \& Palacios, R. (1982). Reiteration of nitrogen fixation gene sequences in Rhizobium phaseoli. Nature, London 299, 724-726.

Quinto, C., de la Vega, H., Flores, M., Leemans, J., Cevallos, M. A., Pardo, M. A., Azpiroz, R., Girard, M. L., Calva, E. \& Palacios, R. (1985). 
Nitrogenase reductase: a functional multigene family in Rhizobium phaseoli. Proceedings of the National Academy of Sciences of the United States of America 82, 1170-1174.

Simon, R., Priefer, U. \& Puhler, A. (1983). A broad host range mobilization system for in vivo genetic engineering: transposon mutagenesis in gram-negative bacteria. Biotechnology 1, 748-791.

SMITH, G. R. (1988). Homologous recombination in procaryotes. Microbiological Reviews 52, 1-28.
Soberón-Chávez, G., NáJera, R., Olivera, H. \& SEgovia, L. (1986). Genetic rearrangements of a Rhizobium phaseoli symbiotic plasmid. Journal of Bacteriology 167, 487-491.

ZeIG, J., Maples, U. F. \& Kushner, S. (1978). Recombinational levels of Escherichia coli K-12 mutants deficient in various replication recombination or repair genes. Journal of Bacteriology 134, 958966. 